\title{
Are the abiotic and biotic characteristics of aquatic mesocosms representative of in situ conditions?
}

\author{
Andrew R. DZIALOWSKI, ${ }^{1 *}$ Marek RZEPECKI, ${ }^{2}$ Iwona KOSTRZEWSKA-SZLAKOWSKA, ${ }^{2}$ \\ Krystyna KALINOWSKA, ${ }^{2}$ Anna PALASH, ${ }^{3}$ Jay T. LENNON ${ }^{4}$
}

${ }^{1}$ Department of Zoology, Oklahoma State University, 501 Life Sciences West, Stillwater, OK 74078, USA; ${ }^{2}$ Nencki Institute of Experimental Biology, Polish Academy of Sciences, 3 Pasteur Street, 02-093 Warszawa, Poland; ${ }^{3}$ The Scientific and Practical Center for Bioresources, National Academy of Sciences of Belarus, ul. Akademicheskaya, 27, Minsk, 220072 Republic of Belarus; ${ }^{4}$ Department of Biology, Indiana University, 1001 E. $3^{\text {rd }}$ Street, Bloomington, IN 47405, USA

*Corresponding author: Andy.dzialowski@okstate.edu

\begin{abstract}
There is debate about whether results from mesocosm studies should be extrapolated to natural ecosystems. Critics argue that the abiotic and biotic characteristics of mesocosms do not represent the in situ conditions of the habitats in which they are designed to mimic. We addressed this idea by deploying mesocosms in two lakes of varying trophic status (mesotrophic and eutrophic). Water chemistry was relatively similar between the mesocosms and the respective lakes. In contrast, biological variables including most phytoplankton, nanoflagellates, ciliates, and zooplankton were lower in the mesocosms than they were in the respective lakes. There was also a shift in zooplankton composition such that mesocosm assemblages diverged from pelagic to littoral communities. While our results show that freshwater planktonic organisms can vary considerably between mesocosms and in situ habitats, we also suggest that factors such as isolation from lake sediments, the lack of predators, and the temporal scale at which mesocosms are filled and sampled should be considered when designing and interpreting mesocosm studies. Nevertheless, mesocosms are an important tool for developing and testing general ecological hypotheses that cannot be achieved using other approaches alone.
\end{abstract}

Key words: Mesocosms, limnocorrals, periphyton, wall effect.

Received: March 2013. Accepted: April 2014.

\section{INTRODUCTION}

Inferences about how natural systems operate under existing and future conditions are dependent on rigorous and replicated experiments, not observations alone. One way to conduct such experiments is through the use of mesocosms, which are designed to mimic key features of natural systems with the goal of bridging the gap between laboratory and whole ecosystem studies (Odum, 1984). However, the utility of mesocosms in ecological research has been a topic of considerable debate over the past several decades. In part, this debate has centered on how well mesocosms represent natural systems, to what degree results from mesocosm studies should be used to make inferences about natural systems, and the overall role that mesocosms should play in understanding natural systems and ecological processes from the level of population to ecosystem (Carpenter, 1996; Schindler, 1998; Carpenter, 1999; Drenner and Mazumder, 1999).

Mesocosms are valuable because they allow researchers to isolate treatment effects by controlling important abiotic and biotic variables. Because of this, mesocosms can be used to study different parts (e.g., populations or communities) of an ecosystem simultaneously (Odum, 1984). Compared to whole ecosystem level stud- ies, mesocosms are also relatively easy and inexpensive to set up and operate. Furthermore, mesocosms offer the potential to rigorously replicate experimental treatments (Drenner and Mazumder, 1999; Huston, 1999). In sum, mesocosms offer opportunities, flexibility, and experimental control, which in many cases cannot be achieved when working in whole ecosystems.

In contrast, mesocosms have been criticized because they lack environmental realism and are usually conducted at temporal and spatial time scales that do not allow for the incorporation of important ecological processes (e.g., mixing, benthic-pelagic coupling, dispersal, succession). For example, mesocosms often exclude lake sediments and large/top predators even though these factors can strongly influence water column processes and/or biological communities. Inter-mesocosm variability can also be high making it difficult to identify treatment effects even when there is rigorous replication (Kraufvelin, 1999). Furthermore, mesocosms have high surface area to volume $(\mathrm{SA}: \mathrm{V})$ ratios and can be overly influenced by biological and chemical processes that occur on their walls (e.g., wall effects) (Carpenter, 1996, 1999; Schindler, 1998; Petersen et al., 1999). For these reasons, it has been argued that mesocosms are oversimplified and not representative of natural systems. 
Regardless of whether scientists agree with the merits of using mesocosms to study and understand ecological processes, the results of these studies have commonly been used in ecological (Ives et al., 1996), evolutionary (Spitze et al., 1991), and toxicological (Caquet et al., 2000) research. Therefore, it is important to understand how abiotic and biotic conditions vary between mesocosms and the habitats in which they are designed to represent. This is particularly important in lentic ecosystems where mesocosms are often placed in situ (e.g., bag and/or limnocorral experiments). We deployed mesocosms that were isolated from lake sediment and lacked vertebrate predators into two lakes over a roughly 6 week period to determine if their abiotic and biotic characteristics were representative of the respective lakes. A better understanding of how mesocosms such as ours differ from the habitats in which they are deployed and designed to mimic, will help identify potential limitation and determine how to better design and interpret mesocosm studies.

\section{METHODS}

\section{Mesocosms}

We constructed thirty-two mesocosms $(0.7 \mathrm{~m}$ diameter and $2.0 \mathrm{~m}$ length) out of polyethylene plastic and deployed them in lakes near the Hydrobiological Station, Mikołajki, Poland. We placed half of the mesocoms in Lake Majcz and half in Lake Jorzec. The lakes were chosen based on their differences in trophic state (Lake Majcz, mesotrophic; Lake Jorzec, eutrophic), proximity to the Hydrobiological Station, and accessability (Rzepecki, 2010). The mesocosms were suspended at the surface of each lake using styrofoam floatation collars so that they were closed on the bottom and isolated from the sediments, but open to the atmosphere at the top. We filled each mesocosm with roughly $750 \mathrm{~L}$ of unfiltered lake water using a gas operated pump. We allowed the mesocosms to equilibrate for approximately three weeks before we sampled them at roughly two-week intervals over a two-month period. We also collected a single water sample for the parameters described below from each lake, on each sampling date at the same depths that were sampled within the mesocosms. These lake data were used to assess differences between the mesocosms and respective lakes (see section Data analysis below).

\section{Water chemistry}

We measured temperature and oxygen from two depths in each mesocosm (the middle and $0.5 \mathrm{~m}$ from the bottom; the two measurements were averaged for each sampling date) using a WTW Multi 3410 Multiprobe Meter with optical sensor FDO925. We also measured conductivity from these depths using a Vario Cond Tetra-
Con $\mathrm{V}$ and $\mathrm{pH}$ of water $(\mathrm{PH}+25)$. $\mathrm{pH}$ was not measured on the final sampling dates because of a malfunction with the probe.

We collected water samples from the center of each mesocosm using a $5 \mathrm{~L}$ Limnos sampler. We used these samples for the analysis of nutrients, algal pigments, nanoflagellates and ciliates (described below). For nutrients, we measured total phosphorus (TP), total Kjeldahl nitrogen (TKN), ammonia nitrogen $\left(\mathrm{NH}_{4}-\mathrm{N}\right)$, and phosphate $\left(\mathrm{PO}_{4}-\mathrm{P}\right)$ according to APHA (2005).

\section{Algal pigments}

Water samples were filtered through Whatman GF/F $(0.7 \mu \mathrm{m}, 4.0 \mathrm{~cm}$ diameter) filters and immediately frozen for analysis of major algal pigments using High Performance Liquid Chromatography (HPLC). Algal pigments were extracted ultrasonically ( 2 min at $10 \mathrm{~W}$, Omni-Ruptor 250 ) in $3 \mathrm{~mL}$ of methanol and analyzed using a Shimadzu HPLC System that was equipped with a UV-VIS and fluorescence detector on a Waters Spherisorb $\mathrm{C}_{18}$ ODS2 column. The pigments were identified by comparison of their retention times and absorption spectra with standards (DHI LAB products) and using data from Jeffrey et al. (1997). Calibration curves were made using external standards.

\section{Nanoflagellates and ciliates}

We fixed water samples with $37 \%$ formaldehyde (final concentration $2 \%$ ) for determinations of nanoflagellate abundances. Samples $(10 \mathrm{~mL})$ were stained with DAPI (final concentration $1 \mu \mathrm{g} \mathrm{mL}^{-1}$; Porter and Feig, 1980), filtered through Millipore $1.2 \mu \mathrm{m}$ pore-size polycarbonate membrane filters, and enumerated by epifluorescence microscopy (Nikon Optiphot 2). We also fixed triplicate water samples with Lugol's solution for determination of ciliate abundances. The samples were decanted to $5-20 \mathrm{~mL}$ and examined with light microscopy (Nikon Optiphot 2) and measurements of ciliates were determined from living material in samples.

\section{Crustaceans}

We collected crustacean zooplankton from two depths in each mesocosm $(0.5 \mathrm{~m}$ below the water surface and 0.5 $\mathrm{m}$ above the bottom of each mesocosm) using a $5 \mathrm{~L} \mathrm{Lim-}$ nos sampler. We filtered samples through a $100-\mu \mathrm{m}$ zooplankton net $(10 \mathrm{~L}$ total $)$ and preserved animals with sugar-buffered formalin. We identified cladocerans and copepods to species when possible.

\section{Data analysis}

We used $t$-tests to compare the water chemistry and biological parameters in the mesocosms and the respective lakes. When necessary, we $\log _{10}$ transformed our data 
to help meet the assumptions of normality and equal variance. The average values from each of the four sample dates from the mesocosms and the four lake samples (one from each date) were used as replicates in these analyses.

\section{RESULTS}

\section{Water chemistry}

In general, the water chemistry in the mesocosms was similar to the water chemistry measured in the respective lakes (Figs. 1 and 2). Temperature, dissolved oxygen, pH, and nutrients (both dissolved and total forms) did not differ between the mesocosms and the respective lakes $(\mathrm{P}>0.1)$. In the mesotrophic system (Lake Majcz) conductivity was significantly higher in the mesocosms than it was in the lake $(\mathrm{P}<0.001)$, but this was not the case for the eutrophic (Jorzec) Lake.

\section{Algal pigments}

The concentrations of algal pigments were significantly lower in the mesocosms than they were in the respective lakes (Fig. 3). Specifically, Cryptophyta $(\mathrm{P}=0.013)$ and Bacillariophyta $(\mathrm{P}=0.019)$ were significantly lower in the mesotrophic mesocosms and Chlorophyceae $(\mathrm{P}<0.001)$, Crypotphyta $(\mathrm{P}=0.002)$, Bacillariophyta $(\mathrm{P}<0.001)$, and Dinophyta $(\mathrm{P}<0.001)$ were significantly lower in the eutrophic mesocosms (Fig. 3).

\section{Nanoflagellates and ciliates}

In the eutrophic system (Lake Jorzec), the abundances of ciliates $(\mathrm{P}=0.007)$ and nanoflagellates $(\mathrm{P}=0.05)$ were significantly lower in the mesocosms than they were in the lake. However, in the mesotrophic system (Lake Majcz), ciliates did not differ between the mesocosms and the lake $(\mathrm{P}>0.05)$, while nanoflagellates were only marginally lower $(\mathrm{P}=0.06)$ in the mesocosms than the lake (Fig. 4).

\section{Crustaceans}

Although copepod abundances did not differ between the mesocosms and the respective lakes $(\mathrm{P}>0.05$ for both lakes), the abundance of cladocerans and nauplii were significantly lower in the mesocosms $(\mathrm{P}<0.05$; Fig. 5). The composition of cladocerans also differed between the mesocosms and respective lakes. Daphnia accounted for a greater percentage of the total abundance of cladocerans in each lake compared to the mesocosms $(\mathrm{P}=0.036$ for the mesotrophic lake and $\mathrm{P}<0.001$ for the eutrophic lake; Tabs. 1 and 2). Several littoral taxa also increased in abundance in the mesocosms. In the eutrophic lake, Chydorus $\mathrm{sp}$. accounted for a greater percentage of the total abundance in the mesocosms than it did in the lake $(\mathrm{P}=0.42$; Tab. 2). Several taxa including Alonella sp. (3\%), Scapholeberis sp. (13\%), and Polyphemus sp. (5\%) in the eu- trophic lake, and Alona affinis (4\%), and Sida sp. (2\%) in the mesotrophic lake were present in the mesocosms but not detected in any of the corresponding lake samples (Tab. 3).

\section{DISCUSSION}

Some scientists criticize mesocosms because they lack environmental realism and do not accurately represent in situ conditions. We tested this notion by comparing the general water chemistry and biological organisms in mesocosms that were deployed in two lakes of varying trophic state. With respect to water chemistry, we found that the mesocosms were relatively similar to the respective lakes (Figs. 1 to 5). These results are somewhat surprising considering that previous studies have shown that nutrient concentrations decline in mesocosms due to sedimentation and/or uptake by attached algae or periphyton on the mesocosm walls (Bloesch et al., 1988). For example, using indoor aquatic mesocosms, Lennon et al. (2003) achieved relatively constant nitrogen and phosphorus concentrations throughout a six-week experiment by replenishing nutrients assuming a daily $5 \%$ loss rate. However, mixing rates may be higher in mesocosms that are suspended in situ compared to land-based mesocosms, which may help to re-suspend nutrients and keep them from settling out of the water column. It is also important to note that the absence of sediments in our mesocosms did not influence nutrient concentrations (Fig. 2) despite the fact that several processes occurring at the sediment-water interface (e.g., the internal recycling of nutrients back into the water column under anoxic conditions) can alter nutrients in the water column (Søndergaard et al., 2001).

In contrast to water chemistry, most of the biological variables were lower in the mesocosms than they were in the respective lakes (Figs. 3 to 5). These results are consistent with a previous 1-month mesocosm study in a humic Polish lake (Jasser and Kostrzewska-Szlakowska, 2012). In that study with larger mesocosms $(0.75 \mathrm{~m}$ diameter, $4.5 \mathrm{~m}$ depth) that similarly lacked sediment and predators, the concentrations of algae, ciliates, crustacean zooplankton, and rotifers were all lower in the mesocosms than they were in the surrounding lake. In contrast to the results from the current study, Jasser and KostrzewskaSzlakowska (2012) also found that nanoflagellates, autotrophic picoplankton, and bacteria were generally more abundant in the mesocosms than they were in the surrounding lake. Similarly, Bloesch et al. (1988) reported that phytoplankton and zooplankton were lower in large lake enclosures than they were in the surrounding lake and that there was a shift from nanoplankton to net-plankton within the phytoplankton community. Bloesch et al. (1998) attributed these differences between mesocosms and the lake to reductions in water movement in the mesocosms, increases in sedimentation rates of particulate car- 
Mesotrophic Lake
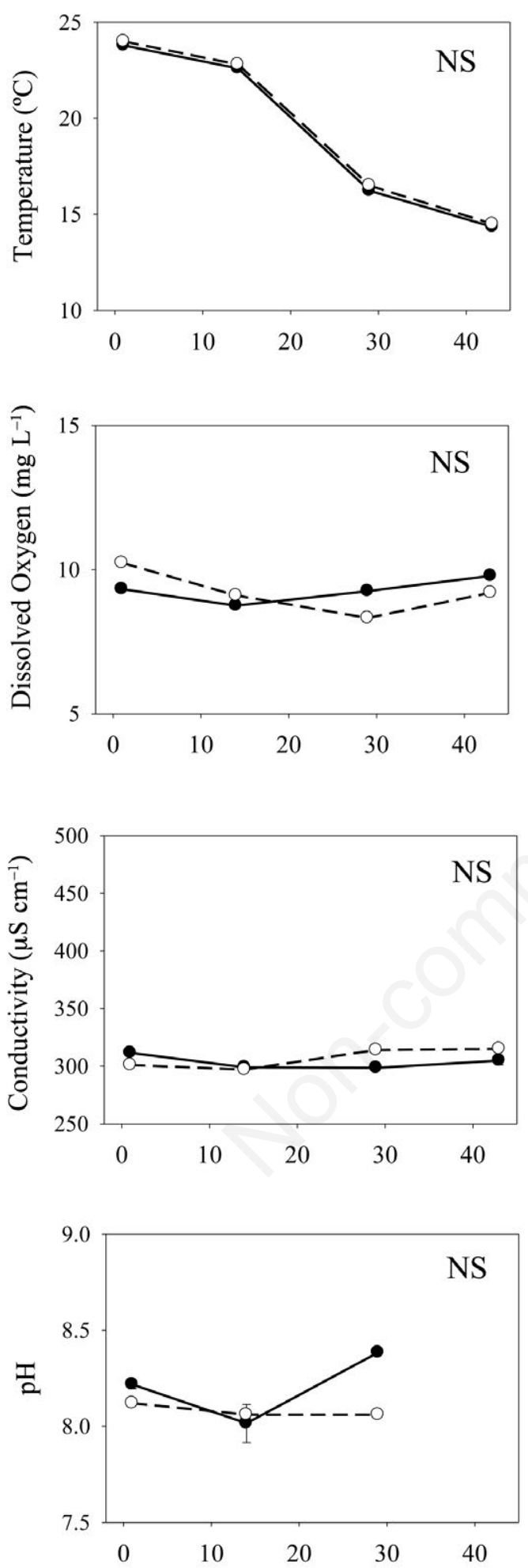

Day
Eutrophic Lake
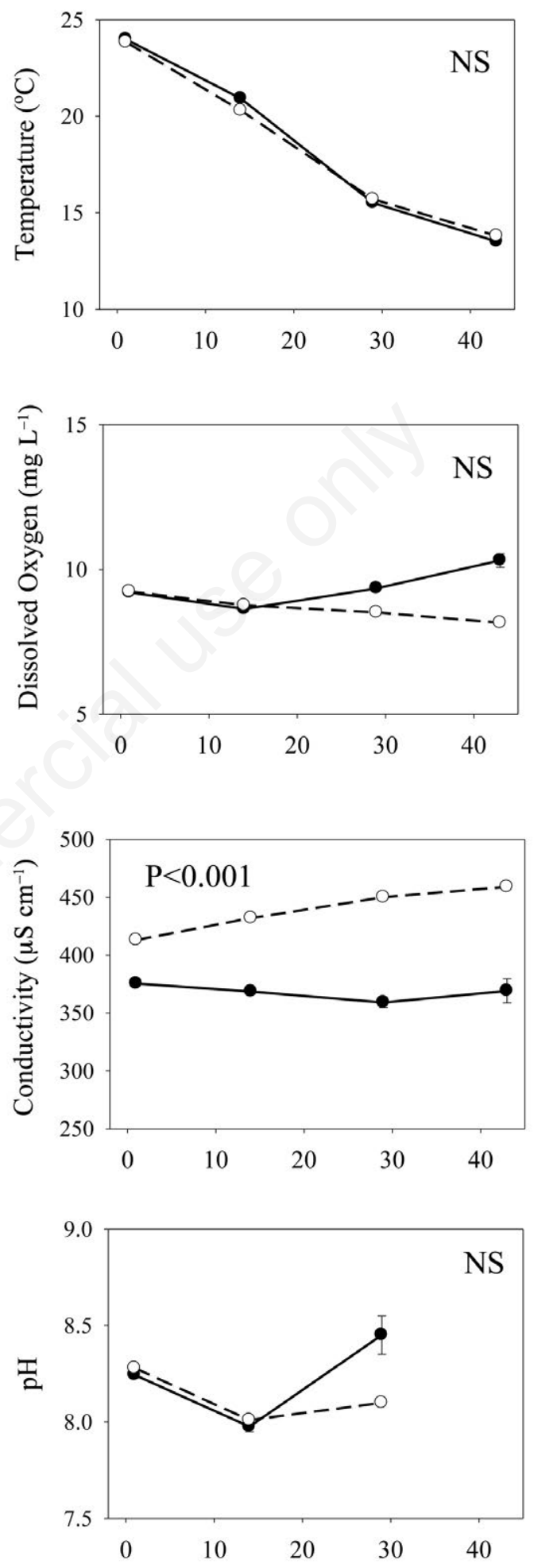

Day

Fig. 1. Comparison of water chemistry in the mesocosms (solid lines) and lakes (dashed lines). Error bars represent standard error of the mean. P-values determined from $t$-tests. NS, not significant at $\mathrm{P}<0.05$. 
Mesotrophic Lake
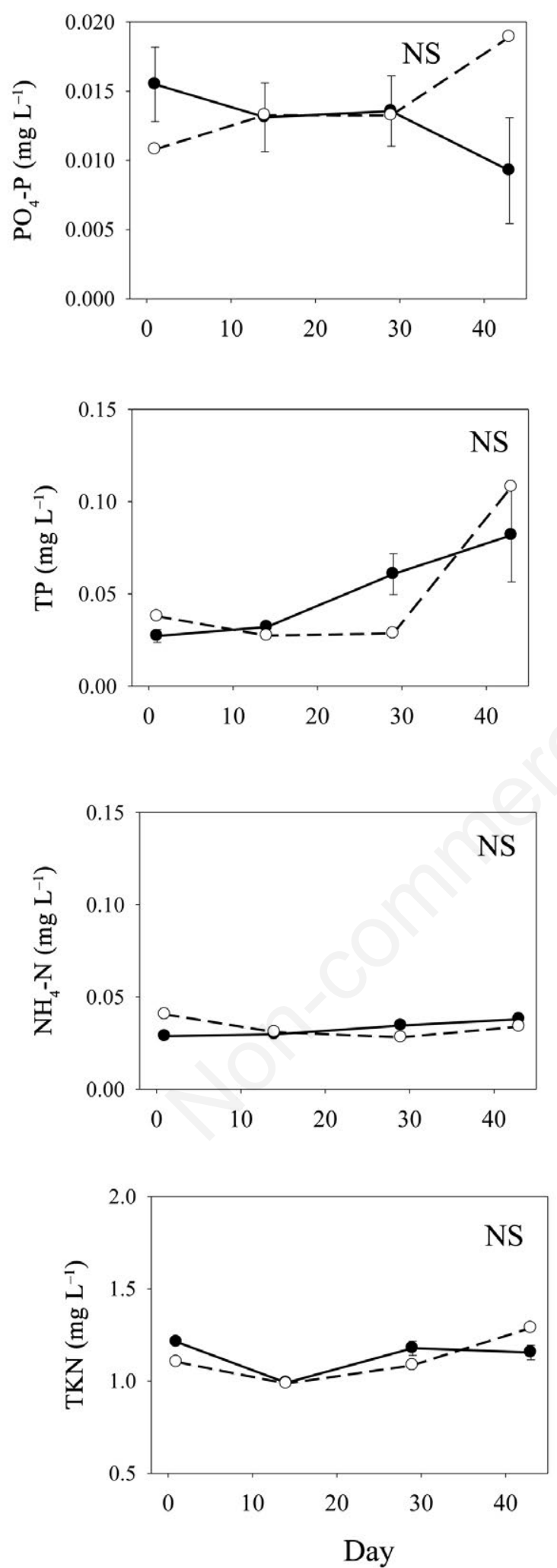

Eutrophic Lake
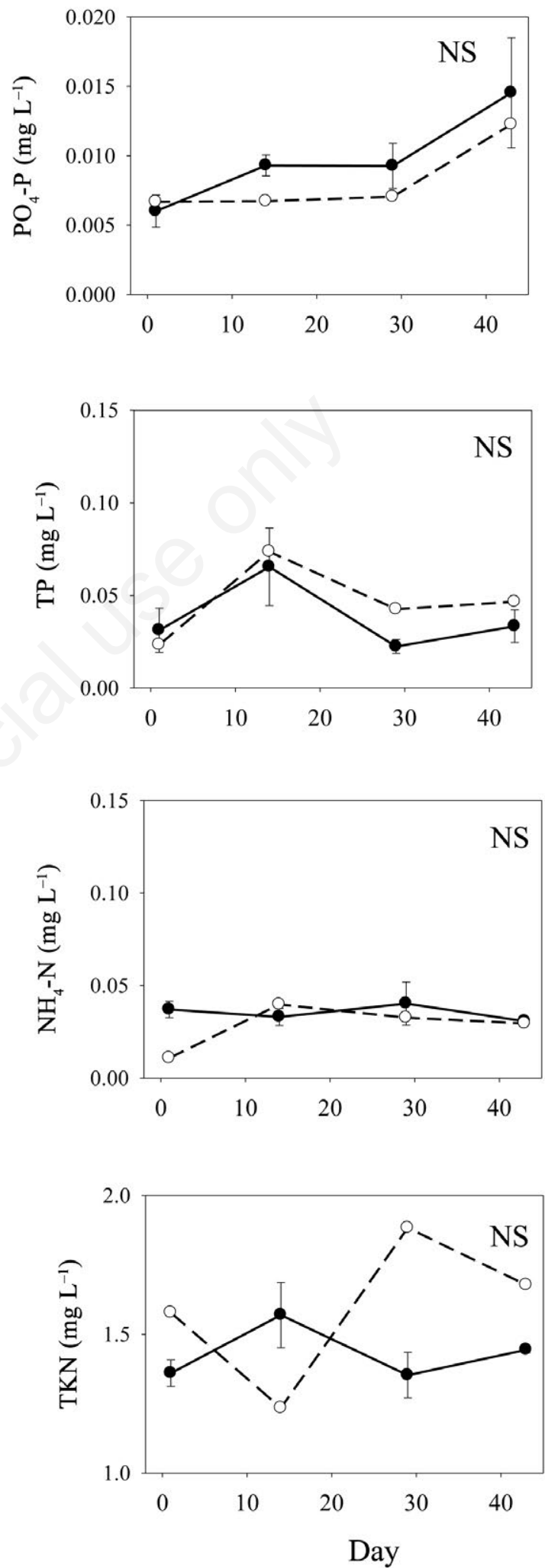

Fig. 2. Comparisons of total and dissolved nutrients in the mesocosms (solid lines) and lakes (dashed lines). Error bars represent standard error of the mean. P-values determined from $t$-tests. NS, not significant at $\mathrm{P}<0.05$. 
Mesotrophic Lake
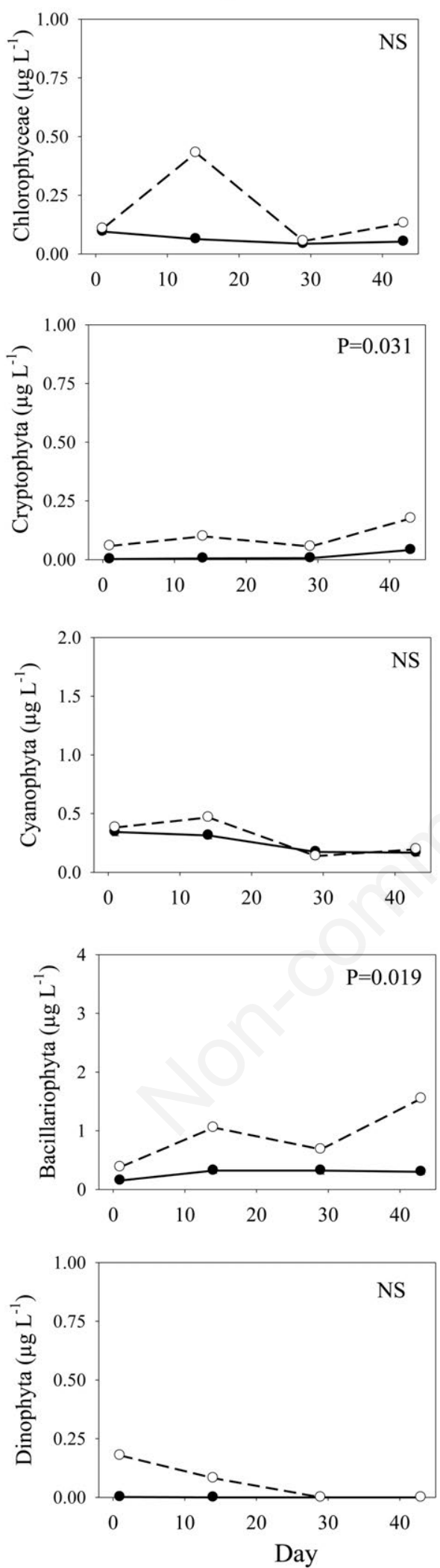

Eutrophic Lake
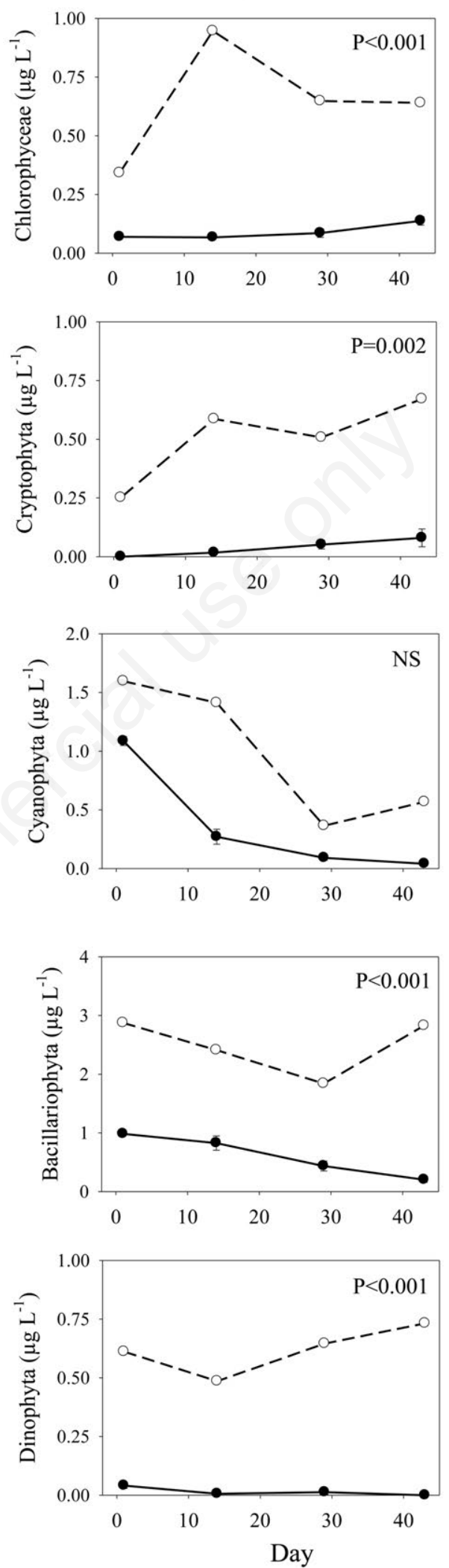

Fig. 3. Comparisons of algal pigments in the mesocosms (solid lines) and lakes (dashed lines). Error bars represent standard error of the mean. $\mathrm{P}$-values determined from $t$-tests. NS, not significant at $\mathrm{P}<0.05$. 
bon and phosphorus, and/or difference in food web structure between the mesocosms and lake.

In addition to a reduction in plankton abundance, we also documented shifts in the composition of zooplankton communities in the mesocosms (Tabs. 1 and 2). These dif-

Tab. 1. Relative abundances of zooplankton ( $\%$ of total abundance) in the mesotrophic lake and the mesocosms. Only taxa that represented at least $2 \%$ of the total abundance are shown. $\mathrm{P}$-values determined from $t$-tests.

\begin{tabular}{lccc}
\hline \multicolumn{4}{c}{ Mesotrophic Lake } \\
\hline Taxa & Lake & Mesocosms & P-value \\
\hline Alona & 0.00 & $3.5(1.3)$ & $* * *$ \\
Bosmina & $17.5(2.34)$ & $16.9(3.2)$ & 0.885 \\
Ceriodaphnia & $49.6(11.3)$ & $50.0(5.6)$ & 0.957 \\
Chydorus & $1.5(0.1)$ & $4.4(1.8)$ & 0.362 \\
Daphnia & $3.8(1.1)$ & $0.8(0.2)$ & 0.036 \\
Diaphanosoma & $26.6(10.7)$ & $18.5(1.7)$ & 0.343 \\
Peracantha & $0.4(0.4)$ & $3.8(1.2)$ & 0.057 \\
Sida & 0.00 & $2.0(0.4)$ & $* * *$ \\
\hline
\end{tabular}

***A species was absent from the lake and statistical analysis was not possible. ferences were consistent for mesocosms in both lakes and were likely related to several factors. First, mesocosms have a higher surface area to volume ratio $(\mathrm{SA}: \mathrm{V})$ than lakes which can lead to wall effects where organisms that favor edge habitats increase in biomass (Chen et al., 1997;

Tab. 2. Relative abundances of zooplankton ( $\%$ of total abundance) in the eutrophic lake and the mesocosms. Only taxa that represented at least $2 \%$ of the total abundance are shown. P-values determined from $t$-tests.

\begin{tabular}{lccc}
\hline \multicolumn{4}{c}{ Eutrophic Lake } \\
\hline Taxa & Lake & Mesocosms & P-value \\
\hline Alonella & 0.00 & $3.2(0.8)$ & $* * *$ \\
Bosmina & $13.3(6.5)$ & $15.4(2.5)$ & 0.728 \\
Ceriodaphnia & $1.4(0.5)$ & $0.7(0.4)$ & 0.393 \\
Chydorus & $12.3(6.5)$ & $38.9(5.8)$ & 0.042 \\
Daphnia & $49.4(5.7)$ & $6.4(2.6)$ & $<0.001$ \\
Diaphanosoma & $23.1(6.1)$ & $18.1(6.3)$ & 0.519 \\
Polyphemus & 0 & $4.6(4.0)$ & $* * *$ \\
Scapholeberis & 0 & $12.5(4.4)$ & $* * *$ \\
\hline
\end{tabular}

***A species was absent from the lake and statistical analysis was not possible.
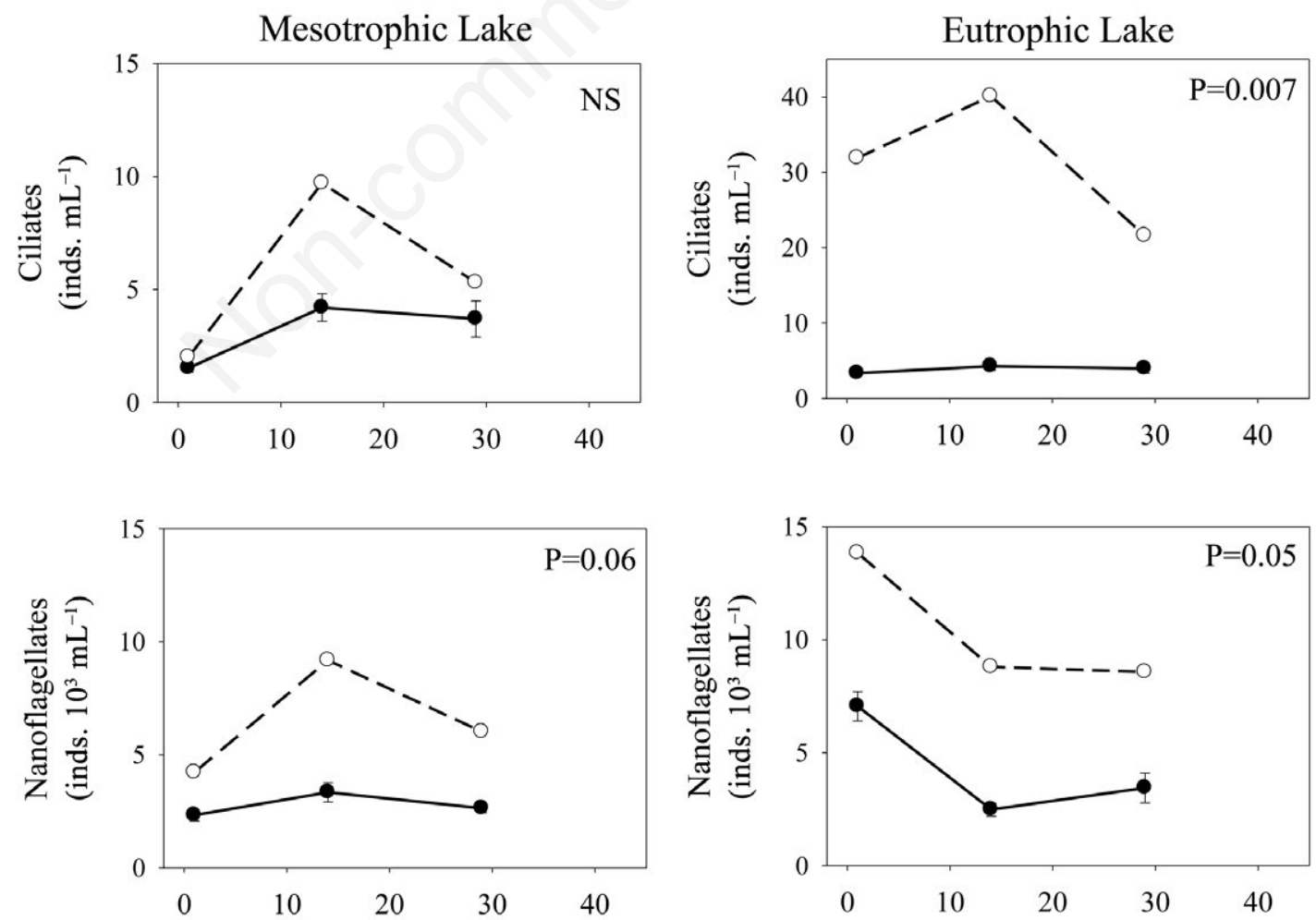

Fig. 4. Comparisons of ciliate and nanoflagellate abundances in the mesocosms (solid lines) and lakes (dashed lines). Error bars represent standard error of the mean. P-values determined from $t$-tests. NS, not significant at $\mathrm{P}<0.05$. 
Petersen et al., 1999). Although not directly quantified, a visual inspection of the mesocosms in both lakes suggested that there was considerable growth of attached algae or periphyton on the side walls. The development of periphyton may have favored littoral zooplankton such as Chydorus that can consume both water column and attached algae (Balcer et al., 1984; Fryer, 199; Smith, 2001). Second, the absence of sediments in the mesocosms may have influenced zooplankton because sediments contain resting eggs that can hatch and maintain the diversity of pelagic zooplankton assemblages (Caceres and Schwalbach, 2001). Sediments can also indirectly in- fluence zooplankton through the release of meroplankton (algal cells found at the sediment/water interface; Schelske et al., 1995) that can serve as a food resource for zooplankton. Finally, both invertebrate and vertebrate predators strongly influence zooplankton (Brooks and Dodson, 1965). Despite this, predators are often excluded from mesocosm studies in part because they exert unrealistically high predation rates (especially vertebrate predators) and/or their abundances are hard to control and manipulate (especially invertebrate predators) (AR Dzialowski, personal observation). Because the goal of the current study was not to tease these mechanisms apart,
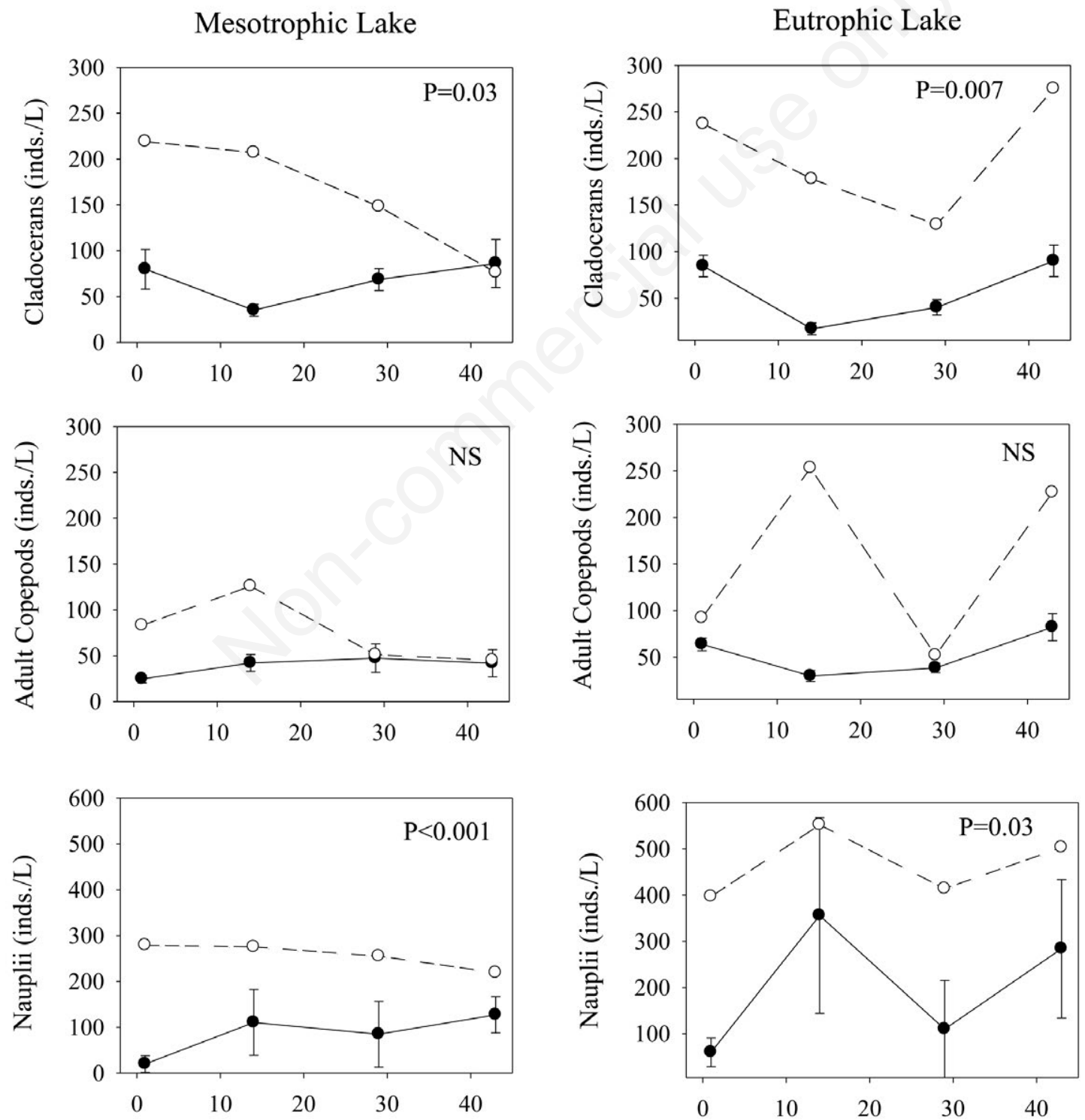

Fig. 5. Comparisons of zooplankton abundances in the mesocosms (solid lines) and lakes (dashed lines). Error bars represent standard error of the mean. P-values determined from $t$-tests. NS, not significant at $\mathrm{P}<0.05$. 
additional experiments are needed that directly manipulate their (i.e., wall periphyton, sediment, and predators) presence and absence to better understand how they contribute to the divergence of biological communities in mesocosms compared to in situ conditions.

A final consideration with respect to the observed differences in the biological communities between the mesocosms and the respective lakes is the temporal scale at which the mesocosms were filled and sampled. Mesocosms exhibit a lifespan during which communities diverge from their starting conditions. We allowed our mesocosms to equilibrate for $\sim 3$ weeks before we collected our first sample. While we feel that an equilibration period is important for mesocosms, 3 weeks may have been too long. For example, if the high SA:V of the mesocosms and associated increases in periphyton favors a shift to littoral zooplankton in the mesocosms, then sampling should be conducted before periphyton growth begins to develop/establish. A better understanding of the temporal dynamics and the rate at which biological communities change in mesocosms relative to in situ conditions will help to determine when mesocosms should be sampled and how long mesocosm experiments should be conducted.

\section{CONCLUSIONS}

Our study highlights differences that can occur between mesocosms and the in situ conditions that they are designed to represent. While the basic water chemistry was relatively similar between the mesocosms and the respective lakes, the abundances and community structure of most planktonic organisms were different. In light of these differences we have identified several areas of research that will help to better understand how the design (e.g., isolation from lake sediments and lack of predators) and sampling schedule (e.g., temporal changes in biological communities in mesocosms) of mesocosms affect their ability to represent natural conditions. Such information should be very insightful for the development, design, and interpretation of future mesocosm studies.

Nonetheless, we believe that mesocosms are an important tool for developing and testing general ecological hypotheses that cannot be achieved using other approaches alone.

\section{ACKNOWLEDGMENTS}

We are grateful to Dr. Irina Feniova and two anonymous reviewers for valuable comments to this paper. We acknowledge the support of the Polish Ministry of Science and Higher Education (N N304 145837).

\section{REFERENCES}

Balcer MD, Korda NL, Dodson SI, 1984. Zooplankton of the Great Lakes. University of Wisconsin Press.
Bloesch J, Bossard P, Bührer H, Bürgi HR, Uehlinger U, 1988. Can results from limnocorral experiments be transferred to in situ conditions? Hydrobiologia 159:297-308.

Boyle TP, Fairchild JF, 1997. The role of mesocosm studies in ecological risk analysis. Ecol. Appl. 7:1009-1102.

Brooks JL, Dodson SI, 1965. Predation, body size, and composition of plankton. Science 150:28-35.

Drenner RW, Mazumder A, 1999. Microcosm experiments have limited relevance for community and ecosystem ecology: comment. Ecology 80:1081-1085.

Caceres CE, Schwalbach MS, 2001. How well do laboratory experiments explain field patterns of zooplankton emergence? Freshwater Biol. 46:1179-1189.

Caquet T, Lagadic L, Sheffield SR, 2000. Mesocosms in ecotoxicology (1): outdoor aquatic systems. Rev. Environ. Contam. T. 165:1-38.

Carpenter SR, 1996. Microcosm experiments have limited relevance for community and ecosystem ecology. Ecology 77:677-680.

Carpenter SR, 1999. Microcosm experiments have limited relevance for community and ecosystem ecology: reply. Ecology 80:1085-1088.

Chen CC, Petersen JE, Kemp WM, 1997. Spatial and temporal scaling of periphyton growth on walls of estuarine mesocosms. Mar. Ecol. Prog. Ser. 155:1-15.

Fryer G, 1991. Functional morphology and the adaptive radiation of the Daphniidae (Branchiopoda: Anomopoda). Philos. T. Roy. Soc. B 331:1-99.

Huston MA, 1999. Microcosm experiments have limited relevance for community and ecosystem ecology: Synthesis of comments. Ecology 80:1088-1089.

Ives AR, Foufopoulos J, Klopfer ED, Klug JL, Palmer TM, 1996. Bottle or big-scale studies: how do we do ecology? Ecology 77:681-685.

Jasser I, Kostrzewska-Szlakowska I, 2012. Fading out of trophic cascade at the base of microbial food web caused by changes in grazing community in mesocosm experiments. Ocean. Hydrob. Stud. 41:1-11.

Jeffrey SW, Mantoura RFC, Wright SW, 1997. Phytoplankton pigments in oceanography. UNESCO Publ.: $661 \mathrm{pp}$.

Kraufvelin T, 1999. Baltic hard bottom mesocosms unplugged: replicability, repeatability and ecological realism examind by non-parametric mutlivariate techniques. J. Exp. Mar. Biol. Ecol. 240:229-258.

Lennon JT, Smith VH, Dzialowski AR, 2003. Invasibility of plankton food webs along a trophic state gradient. Oikos 102:191-203.

Odum EP, 1984. The mesocosm. BioScience 34:558-562.

Porter KG, Feig YS, 1980. The use of DAPI for identifying and counting aquatic microflora. Limnol. Oceanogr. 25:943-948.

Petersen JE, Cornwell JC, Kemp WM, 1999. Implicit scaling in the design of experimental aquatic ecosystems. Oikos 85:3-18.

Rzepecki M, 2010. Dynamics of phosphorus in lacustrine sediments: contents and fractions in relation to lake trophic state and chemical composition of bottom deposits. Pol. J. Ecol. 58:529-548.

Schelske CL, Carrick HJ, Aldridge FJ, 1995. Can wind-induced resuspension of meroplankton affect phytoplankton dynamics? J. N. Am. Benthol. Soc. 14:616-630. 
Schindler DW, 1998. Replication versus realism: the need for ecosystem-scale experiments. Ecosystems 1:323-334.

Smith DG, 2001. Pennak's freshwater invertebrates of the United States: Porifera to Crustacea, $4^{\text {th }}$ ed. J. Wiley \& Sons: 648 pp. Søndergaard M, Jensen JP, Jeppesen E, 2001. Retention and in- ternal loading of phosphorus in shallow, eutrophic lakes. Scientific World Journal 1:427-442.

Spitze L, Burnson J, Lynch M, 1991. The covariance structure of life history characters in Daphnia pulex. Evolution 45:1081-1090. 